\section{Insult and injury}

\author{
Stephen H. Schneider
}

The Greenhouse Effect, Climatic Change, and Ecosystems. SCOPE 29. Edited by Bert Bolin, Bo R. Doos, Jill Jager and Richard A. Warrick. Wiley: 1987. Pp.541. $\$ 110, £ 56$.

IN October 1985, an international conference of potentially major importance took place in Villach, Austria. The first conclusion of the conference report read:

Many important economic and social decisions are being made today on long-term projects major water resource management activities such as irrigation and hydro-power, drought relief, agricultural land use, structural designs and coastal engineering projects, and energy planning - all based on the assumption that past climatic data, without modification, are a reliable guide to the future. This is no longer a good assumption since the increasing concentrations of greenhouse gases are expected to cause a significant warming of the global climate in the next century. It is a matter of urgency to refine estimates of future climate conditions to improve these conditions.

The implications of such important changes, the conference concluded, "could be profoundly affected by governmental policies on energy conservation, use of fossil fuels, and the emission of some greenhouse gases". The report went on to recommend major studies of the effects on the environment and society of $\mathrm{CO}$, and potential ways to control it and other trace gases. After acknowledging that "major uncertainties remain in predictions of changes in global and regional precipitation and temperature patterns", the report concluded: "nevertheless, the understanding of the green- house question is sufficiently developed that scientists and policy makers should begin an active collaboration to explore the effectiveness of alternative policies".

What, then, is the scientific basis of such bold and pointed conclusions? The next 540 pages of this volume attempt to make the scientific case for the recommendations of the Villach conference. The book presents ten background papers written by well-known scientists for the purpose of summarizing the state-of-theart in their respective fields. As well as a summary chapter on the greenhouse effect, these include: climatic change and ecosystems issues; emission of $\mathrm{CO}_{2}$ into the atmosphere; carbon cycle projections of how much $\mathrm{CO}_{2}$ might remain in the atmosphere; other trace greenhouse gases and aerosols; modelling of the future climate system; empirical studies, analogues and signal detection issues; changing sea level; impacts on ecosystems; relationship to agriculture; and, finally, relationship to global forests.

These chapters are, for the most part, well-presented critical surveys of the areas they consider. Chapter 3, for example, on the carbon cycle, by Bert Bolin, is beautifully written and comprehensive - as we have come to expect from its author. It does not, however, include a discussion of the validity of simple one-dimensional box models for long-term biochemical projections. Although Robert Dickinson's chapter is so comprehensive that I can't easily think of any important climate modelling issue it neglects, it leads off with a differential equation and probably can be fully understood only by analytically trained scientists. But his critical evaluation of the strengths and weaknesses of modelling is first rate, and 'bottom line' valid (even if

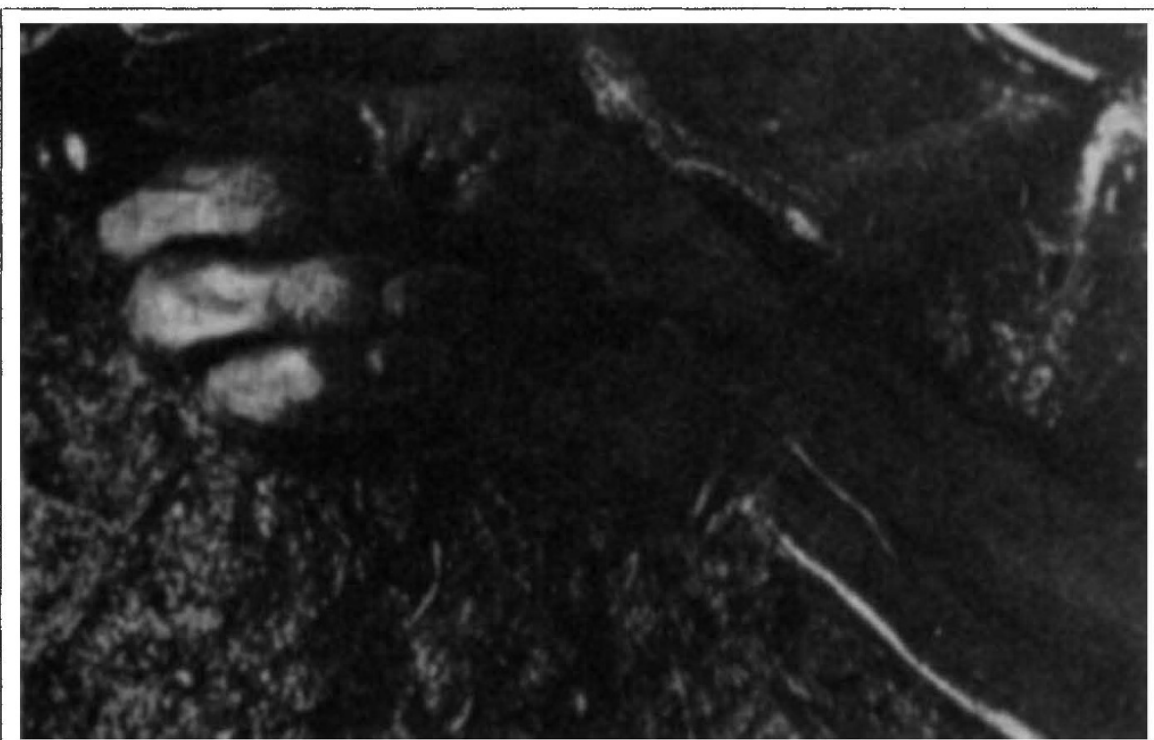

An accusing finger - the right hand of Grauballe man, whose throat was cut and whose body was buried in the Jutland peat bog c. 1,600 years ago. The unworn fingernails suggest that he was not a manual worker. The picture is taken from European Wetlands in Prehistory edited by John $M$. Coles and Andrew J. Lawson, just published by Clarendon Press. Price is $£ 50$. downbeat): "The present $\mathrm{CO}_{2}$ warming signal should lie approximately between 0.3 and $1.1^{\circ} \mathrm{C}$. None of the GCM model results for regional pattern is yet sufficiently certain as to suggest useful regional 'fingerprints' for the warming signal". Similar statements of uncertainty could be quoted from the other chapters, which at the very least provide good up-to-date overviews and excellent reference lists.

As comprehensive as the list of chapters sounds, there are important areas that are not covered. For example, although soil moisture and water supply are mentioned in various chapters, a turn to the index shows that most of the headings containing the word "water" occur in the chapter on sea-level rise, and are not related to the long-term economic planning and user implications of plausible changes to water supply systems. This topic may well prove to be one of the most important issues of trace-greenhouse-gas impacts, and indeed was certainly worthy of a detailed chapter or two to deal, amongst other matters, with the social and political restraints on the rational management of current water supplies. Also missing is coverage of another potentially important issue, the possible direct consequences for health of greenhouse warming: change in disease vectors, morbidity and mortality associated with runs of heat-stress days, and so on. Both of these topics probably deserved their own chapters, although it must be admitted that very little comprehensive work has been done in the latter area, so the editors cannot be faulted for having difficulty in finding people to write about it.

Also in need of more emphasis is a sense of the context of climatic changes for the global economy, and the intrinsic interconnection between increasing levels of trace gases, especially $\mathrm{CO}_{2}$, and the problem of global economic development. Quite simply, population resources and environmental problems form an integrated set of which climate change is but a part. No nation acting alone can make much difference beyond temporarily slowing down the build-up. Furthermore, any talk of restraint on population size or development in less-developed countries is divisive in the absence of forthright discussion of alternative pathways towards development. This is one of the primary reasons that it is so difficult to achieve a global consensus on how to deal with various trace-gas-producing activities. Developed countries cannot ask the underdeveloped world to re-chart its development expectations simply because of the possibility of effects of global pollution, without at the same time moderating their own profligate consumption of resources. Ultimately, a bargain between rich and poor nations is needed.

One example I have previously discussed - for example, see The Coevolution 